\title{
Preparing for Parenthood; Parenting Training Module on six Child Development Aspect in East Jakarta
}

\author{
Yenina Akmal ${ }^{1}$ \\ Universitas Negeri Jakarta \\ Hikmah $^{2}$ \\ Universitas Negeri Jakarta \\ Astari $^{3}$ \\ Universitas Negeri Jakarta \\ Ichtineza Halida Hardono ${ }^{4}$ \\ Universitas Negeri Jakarta
}

DOI: https://doi.org/10.21009/JPUD.132.12

Accepted: August $15^{\text {th }} 2019$. Approved: September $4^{\text {th }} 2019$. Published: $30^{\text {th }}$ November 2019

\begin{abstract}
The age period of $0-8$ years is the most important moment for every human being to develop all the developmental features supported by parents at home and teachers / tutors at the Early Childhood Education Institute (ECE). In parenting, six main aspects must be known and applied by each parent. Lack of education, nutritional knowledge, care and care, and aspects of clean-living habits in the family can have an impact on children's growth and development processes. This study aims to develop a module 6 aspects of child development for parental guidance. This study uses a research and development approach to test the effectiveness of the posttest design. Respondents in this study are parents who have children up to 5 years and early childhood educators. The findings show that from these six main aspects, it seems that parents and ECE tutors do not yet understand the ECE concept. In another perspective, there is still a lack of knowledge about these 6 main aspects which require training and parenting modules to develop the 6 aspects of child development.
\end{abstract}

Keywords: Early Childhood Education, Child Development Aspect, Parenting Training Module

\footnotetext{
${ }^{1}$ Corresponding Author:

Email: yenina.akmal@yahoo.com
} 


\section{INTRODUCTION}

Variables that improve social and emotional health in infancy and early childhood, at a minimum are the basic resources in the family home environment need to be fulfilled. Families must have food, housing, clothing, and medical care and childcare that is easily accessible to ensure that attention can be given to meeting the care of children. The lack of resources and knowledge in parenting puts excessive pressure on parents and early childhood and puts children's social, emotional, and cognitive development at ongoing risk. A child must experience parenting interactions and relationships, at least one, in a family context. Morris \& Williamson, (2019)'s scientific studies identify that sensitive and responsive care leads to the safety of children in parent-child relationships, promoting social and emotional well-being.

The transition to parenthood is a challenging and stressful time for many couples. Interventions and other resources to help parents face these challenges have the potential to provide great benefits. For example, in a family of two parents, increasing the ability of parenthood to minimize daily stress, negative influences, and conflict in their relationships can provide a more stable context and enrich children's development (Jones et al., 2018). Co-parenting - how couples relate to each other in their shared roles as parents - is a prediction of various family and child outcomes. Sheedy \& Gambrel, (2019)'s research tries to understand how couples negotiate co-parenting relationships during the transition to parenthood. The relationship between the two parents is the key to improving the six aspects of child development. A stable relationship between parents depends on the ability to regulate the emotions of each partner. Rutherford, Wallace, Laurent, \& Mayes, (2015) examines the role of emotional regulation in parenting, taking into account the unique demands for caring for children and recognizing that parents must facilitate regulation in children, especially early in development so that children can complete their developmental tasks. Childcare programs require parental emotional stability for a child's well-developed success.

The Indonesian Human Development Index (HDI) ranked 113 out of 180 countries in the World (UNDP, 2018). Some of HDI assessment indicators consist of economic, education, and health aspects. Those indicators show that there must be full attention to the improvement of Indonesia's human resources, which must start at an early age. Meanwhile, data from the Directorate of NonFormal Education recorded that the number of early childhoods in 2008/2009 was $29,847,739$. The Ministry of Health data in 2017 showed that around 27.77 million (10.64\%) of Indonesia's population lives below the poverty line. Low levels of education (averaged junior high school) surely have an impact on the level of early childhood health. The latest data in 2015, according to the Ministry of Health, showed that the maternal mortality rate was quite high, around $305 / 100,000$ births. Moreover, the Statistics Indonesia 2016 showed that the infant mortality rate in 2016 was around 25.5/1000 births. These conditions undoubtedly have an impact on early childhood development programs, where children need good nutrition and proper care and nurture so they can grow into a high-quality generation.

Latest comprehensive analysis of early childhood development interventions in five sectors of health, nutrition, education, child protection, and social protection. The (Britto et al., 2017) review concluded that to make childcare interventions successful, intelligent and sustainable, it needs to be implemented as a multi-sectoral intervention package that is tethered to the method of early childhood care. While interventions will continue to increase with the development of developmental science, the evidence now strongly suggests that parents, caregivers, and families need to be supported in providing care nurturing and protection for small children to achieve their developmental potential. 
Parenting quality - an environment of warmth, responsiveness, and stimulation of children - encourages the cognitive, social, and emotional development of young children. But how to provide care programs in low- and middle-income countries (LMICs) to produce a larger effect size and consistency in improvements in early childhood development. Knauer, Ozer, Dow, \& Fernald, (2019)'s longitudinal study found that parental warmth and responsiveness in infancy were significant predictors of a child's development at 3-5 years of age. during the prekindergarten period, the practice of parent stimulation is a significant predictor of concurrent child development. The findings indicate the importance of quality caregiving throughout childhood, and that the effects of aspects of care can vary from infants to prekindergarten. Programs or training that target parents of young children must adapt their curriculum to the specific age of the targeted child.

This research is an advanced research with a broader field. From the results of previous studies, namely in 2016 and 2017 in East Jakarta (Rawamangun and Duren Sawit), it is known that young mothers in the ECE institution did not apply their concept of daily care (parenting and childcare and nutrition knowledge) (Akmal 2017; Akmal 2017). That's because the insight or information received is not detailed (too general or too rough) and is obtained through conversation in the daily lives of young mothers. In addition, there is also a lack of desire to learn and read news from various social media related to parental concepts. Therefore, this study was conducted to find out the extent and knowledge and understanding of parents and ECE tutors about care related to the six main aspects, by developing a fun, meaningful, and contextual Early Childhood Training Module, and testing the effectiveness of module development. Early Childhood Care Training Module and its relationship to six aspects of child development for parents and ECE tutors.

\section{THEORITICAL STUDY}

\subsection{The Importance of Parenthood in Early Childhood Development}

New parent education programs use home visits, but the high cost of this intensive approach can be a barrier to providing parenting education to parents. Gilmer et al., (2016) identifies effective and efficient new parental education approaches that can realistically be given at a universal level as well as evaluations that identify educational programs or processes that meet parental criteria in understanding stimulation aspects of child development. Interventions to support parenthood to function properly and prevent the transmission of negative care models from generation to generation and promote child development and overall family health. Increasing the number of divorces, poverty, substance abuse, and mental health problems among parents increases the risk of neglect and child abuse. New interventions that are effective, preventive and promote health are urgently needed to support families with young children. Kalland, Fagerlund, Von Koskull, \& Pajulo, (2016)'s research provides a theoretical understanding of the importance of parental mentality for the development of parent-child relationships and child development and proposed action mechanisms for increasing mental capacity.

The longitudinal study by Kopala-Sibley et al., (2018) investigated the mothers who also reported the behavior of their 3-year-old children. mothers who care for children with hostility, record the results of unfavorable cognitive development in children. Conversely, mothers who have regulations in parenting result in an increase in children's brain connectivity. The results showed parenting was associated with changes in parental emotions and parenting influenced the connectivity of the child's brain. Therefore, it is important to provide guidance to parents through various 
intervention programs and parenting training for parents as a provision to care for young children positively.

Grindal et al., (2016) study examines the potential additional benefits of parenting education for parents, the most common form of parent-focused services provided by preschool programs (parenting programs), on the development of children's cognitive and pre-academic skills. The results show that childcare education that provides examples or opportunities to practice positive interactions with children will have a stronger additional impact than parental education programs; and second, the impact of cognitive improvement on children will increase with the intensity and frequency of parenting education provided.

Another important thing from parenting in early childhood is the theory of the cyclical relationship between parent and child interaction with violence and coercion and behavioral problems that begin in early childhood. Coercive interactions have been theorized and were found to facilitate the development and growth of early behavioral problems in children, parenting program interventions for parents from the outset often target childcare to prevent or reduce the initial behavioral problems that interfere. Sitnick et al., (2015)'s findings provide longitudinal confirmation that increasing positive involvement in parent-child interactions can reduce children's growth in problematic behavior.

Today's economic phenomena also contribute to the importance of parenthood knowledge for parents in the millennial era. Psychological parents (parental stress, depression, and social support from friends and family) increasingly show the importance of parenting knowledge among highrisk families. Theise et al., (2014) findings show that parents with less psychological resources are likely to benefit from special programs on parenting provided by the school or government in order to deal with various problems in childcare. Parent-focused and family-based intervention programs promise to strengthen care among the families with the highest risk.

\subsection{Parenting Training Module on Six Child Development Aspect}

Families with disadvantaged socio-economic backgrounds and ethnic minorities are often difficult to reach for the prevention and handling of disturbing child behavior problems. Parenting programs that are carried out for parents give results in reducing disruptive behavior in children. Successful parents in program implementation such as increasing the use of praise and reducing harsh discipline show results in the form of changes in children's behavior. Such a study by (Leijten, Raaijmakers, Orobio de Castro, van den Ban, \& Matthys, 2017) shows that ethnic minority families who are socially and economically disadvantaged in disadvantaged environments can be involved and benefit from parenting programs for childcare interventions to reduce disruptive child behavior.

Parenting training for parents has been developed in many countries. The rapid global spread of parenting programs in childcare interventions, but little is known about their effectiveness when transported to countries that are different from where they came from, or about factors that influence success. The first systematic effort to overcome this problem, focusing on interventions to reduce child behavior problems. Gardner, Montgomery, \& Knerr, (2016)'s results found a higher effect in countries with families where childcare values are focused on survival compared to countries that rank more individually. Contrary to popular belief, parenting programs for childcare interventions appear to be at least as effective when transported to countries that are more culturally different, and in-service provision, than interventions in which they are developed. 
The development of the parenting program module is also based on the growing development of child abuse which has become a global problem affecting high-income countries (HIC) and low and middle-income countries (LMICs). Research has shown that children who live in the poorest countries and communities in the world are more likely to suffer abuse and neglect. There is some evidence that parenting training programs on childcare interventions can help in the prevention of child abuse, but most of this research has been conducted at HICs. The findings show that parenting programs have the potential to prevent and reduce the risk of child abuse. However, there is a lack of good evidence from LMICs where the risk of child abuse is greatest (Coore Desai, Reece, \& Shakespeare-Pellington, 2017).

The preparation of the parenting training module is also based on the results of research that the parenting program can influence parenting patterns that have an impact on the development of the child's executive function, cognitive development and behavior. Lucassen et al., (2015) investigated the relationship between strict childcare and sensitive childcare practices and the executive function of children (EF) in early childhood in 607 families. The results show parenting that is less sensitive than the mother and parenting that is harder than the father's is associated with lower metacognition scores and self-control that is inhibiting. Parenting is not associated with child flexibility. This study extends previous research on the relationship between childcare and EF with a focus on the role of fathers and shows the independent effect of mothers and fathers on EF children.

The Parenting Program Module, in addition to providing knowledge to parents on how to improve cognitive aspects or executive functions, this module also provides knowledge on other aspects such as children's social emotions. Although there are many children who are affected by anxiety and depression, the trajectory of the development of internalization disorders is not well understood. The study applied a group-based modeling approach to examine the interaction between the temperamental nature of negative emotions and parenting on the symptoms of internalization from early childhood to adolescence. Interestingly, children with high negative emotions are more likely to be group members with high levels of internalization symptoms if their mothers show high warmth / sensitivity. The research findings add to the understanding of the developmental pathway of internalization problems from childhood to adolescence by suggesting that a combination of tempera and certain childcare can increase the tendency of adolescents to develop internalization problems (Davis, Votruba-Drzal, \& Silk, 2015).

Likewise, the behavioral content in the parenting training module is based on research conducted by Guyer et al., (2015) research on behavioral inhibition (BI) is a temperament that is characterized by social aversion and withdrawal from a foreign or novel context and carries risk for social anxiety disorder. Developmental outcomes related to this temperament can be influenced by the context of childcare. The convergence of a child's temperament disposition and caregiving environment is finally expressed at the level of behavior and nerves in emotional and cognitive response patterns to social challenges. In contrast, all adolescents showed decreased custodial responses to peer rejection at higher levels of care. These findings indicate that BI in early life is associated with greater neurological sensitivity to differences in parenting styles, especially harsh parenting.

The relationship between symptoms of child externalization, disruptive maternal care, and control of children's efforts was examined. Both disruptive care and low child endeavors have been linked to psychopathology, but the problem of externalizing children and low child endeavors may affect 
the quality of care and each other. This finding is consistent with the view that externalizing children's behavior undermines children's efforts and contributes to be a nagging mother and that the relationship between disruptive parents and children's effort is two-way at all times. Thus, parenting programs for interventions that focus on modifying the problem of externalizing children (as well as the quality of care) can influence the quality of care received. The Parenting Program Module developed by researchers is expected to be able to provide knowledge that inspires parents to raise their children to be superior (Eisenberg, Taylor, Widaman, \& Spinrad, 2015). Semistructured observations by Sulik, Blair, Mills-Koonce, Berry, \& Greenberg, (2015) about caregiving prospectively estimating performance on a set of executive function tasks and the primary caregiver report on externalizing behavior. In addition, the relationship between early childcare and externalizing behavior is mediated longitudinally by the executive function, providing support for a process model where sensitive care promotes children's self-regulation, which in turn reduces the child's externalizing behavior.

The developing children's brains are very sensitive to the input from their social environment. Maintaining social experience enhances the acquisition of social and cognitive skills and emotional competence. However, many young children are faced with unhealthy development, including poverty, improper care, and violence, and increased sensitivity to the social environment means that children are very vulnerable to adverse childhood experiences. One source of social difficulties in a child's life can come from strong, inconsistent, insensitive or hostile parenting. Parenting is seen as a cornerstone of early socio-emotional development and poor parenting style is associated with adjustment problems and a higher risk for developing moods and behavior disorders. The growing literature shows that an important predictor of parenting behavior is how parents, especially mothers, become parents themselves.

Lomanowska, Boivin, Hertzman, \& Fleming, (2017) examines how difficulties in early life influence later parenting behavior and how these effects can continue between generations. The psychological basics of parenting, including responsiveness to young people, executive functions and influences, as well as physiological mediators of parenting behavior, including hormones, brain regions and neurotransmitters, and how developments in this relevant domain can be influenced by difficulties experienced early in life. Genes and early experiences interact to predict maternal behavior, including the involvement of epigenetic mechanisms. Understanding how adverse parenting breeds the next generation of harmful parenting is very important to design interventions that aim to prevent this intergenerational cycle of early generation between generations.

The parenting training module contains the level of achievement of child development standards, which is the first standard that must be considered. Child development achieved is the integration of aspects of understanding religious and moral values, cognitive, language, social emotions, physical motor and art. Early childhood development and growth are unique and individual therefore their needs are also individual. To stimulate learning can be grouped by age, such as childcare for children aged 0-2 years, play groups 3-4 years, kindergarten age groups 5-6 years (Kurniah, Andreswari, \& Kusumah, 2019).

\subsubsection{Social Emotional Development Aspect}

Parents need to be trained in how to measure social and emotional development in early childhood. The parenting training module needs to describe the relationship of social and emotional development to children's functioning and overall well-being, and then present the main measure- 
ment challenges associated with this domain, including the lack of clarity around the conceptualization of subdomains of social and emotional development, and issues related to quality and ease of use for actions that still exist (Darling-Churchill \& Lippman, 2016).

Children's social competence is the ability to build and maintain social contact in the process of interaction on the basis of a positive self-attitude. Communicative competence, or competence in interaction, is a system of psychological knowledge about self and others, communication skills, behavioral strategies for social situations, which allows building effective communication in accordance with the goals and objectives of interpersonal interaction. Emotional intelligence is the ability to experience emotions, to understand the emotions of others and others and to regulate their expressions. Emotional literacy is a combination of knowledge and skills needed for adequate perception of communicative situations, evaluation and emotional expression (Parhomenko, 2014).

\subsubsection{Physical and Motor Development Aspect}

The child's physical and motor development must be considered in certain contexts. Crawling and learning to walk illustrate how much mother's daily practice in raising children is important to master the motor physical development benchmarks of children. Parents also need to understand the maturation of the child's brain and nerve structure which produces a beneficial effect on strength and balance by increasing the speed and efficiency of information processing. The relationship between motor development and brain growth is mainly expressed at the age of the baby, and this can also be attributed to the accelerated growth of the unique cerebellum (Đorđić, Tubić, \& Jakšić, 2016). Parents need knowledge in improving children's independent walks which increase children's mobility and opportunities for social interaction, while motor development in general has a significant effect on children's cognitive and language development.

\subsubsection{Moral Development Aspect}

Moral development can be considered as a process of developing behavior regulation based on an internalized norm system. In the cognitive aspect it is knowledge of the norms and consequences of violating the norm, in the emotional aspect the orientation to emotional feelings about the cognitive approach starts from J. Piaget cognitive and intellectual structure, moral judgment and moral reasoning. These ideas are embodied in the theory of developing moral awareness proposed by L. Kohlberg. Childhood is an important time for humans in moral norms and moral development at that age. Social-cognitive psychological development in childhood provides the conditions necessary for moral development. The development of social relations and communication with peers at an early age plays an important role in moral development (Molchanov, 2013).

\subsubsection{Cognitive Development and Nutrition}

Jürges' research in education, health, and development economics has highlighted the important role of early health (at all stages of infancy and childhood) in human cognitive and non-cognitive development and later life outcomes. The importance of the initial state of life has been shown both theoretically to provide credible evidence from cleverly designed observational data and field experiments. This literature also highlights the importance of policy interventions that can improve educational attainment through better child health. Most existing studies on the relationship between health and cognitive development in developed and developing countries have focused on physical health. Compared with the effects of poor physical health, e.g., malnutrition or 
childhood infections, on cognitive development, little is known about the relationship between poor mental health in children and long-term outcomes that are mediated mainly through cognitive development. Therefore in the parenting training module, it is necessary to instill knowledge in parents about proper nutrition and stimulation for children. (Jürges, Schwarz, Cahan, \& Abdeen, 2019)

\subsection{Parenting Training Module}

The following is the conceptual model design of the parenting training module:

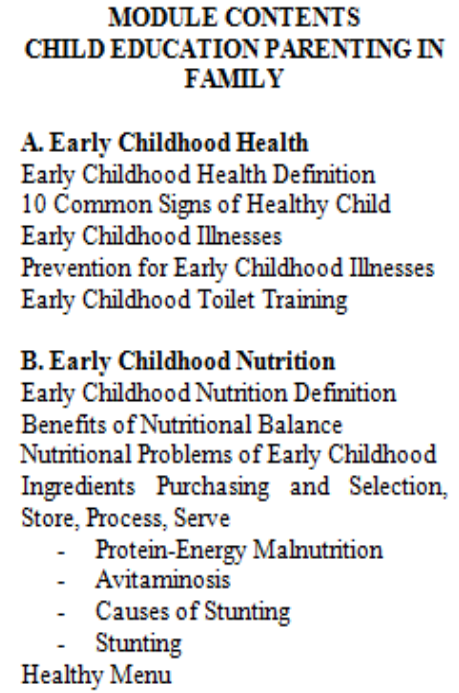

A. Early Childhood Health

Early Childhood Health Definition

10 Common Signs of Healthy Child

Early Childhood Illnesses

Prevention for Early Childhood Illnesses

Early Childhood Toilet Training

B. Early Childhood Nutrition

Early Childhood Nutrition Definition

Benefits of Nutritional Balance

Nutritional Problems of Early Childhood

Ingredients Purchasing and Selection,

Store, Process, Serve

- Protein-Energy Malnutrition

- Avitaminosis

- Causes of Stunting

- Stunting

Healthy Menu

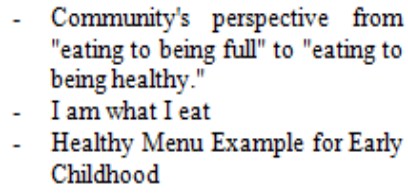

- Community's perspective from "eating to being full" to "eating to being healthy."

- I am what I eat

- Healthy Menu Example for Early Childhood

\section{Parenting Style}

Parenting Style Definition

Parenting Style Goals

Types and Examples of Parenting Style

\section{Stages of Development}

Early Childhood Definition

Characteristics of Early Childhood

Golden Generation

6 Aspects of Early Childhood

Development

E. Parenting Concept

Role of Parents in Childcare

Role of Father

Role of Mother
Role of Child

Mother-Child Attachment

Father-Child Attachment

F. Characteristics

Obey and Respect Parents (example of figures)

Help Fellow Friends

Mutual Respect

Say Thank You

Help Troubled People

Apologize When Making Mistakes

Ask for Permission

Maintain Relationships

P.S. Please provide any additional aspects that need to be focused or added to the table of contents above.

Thank you

Yenina Akmal

Figure 1. Contents of Early Childhood Parenting Training Module

EARLY CHILDHOOD PARENTING MODULE PREPARING FOR PARENTHOOD

MODULE 1 ECE Concept

1. Child Education in Family

2. Role of Parents

3. Parenting Style

MODULE 2 Early Childhood Development

1. Cognitive Development

2. Religion and Morality Development

3. Linguistic Development

4. Physical Motor Development

5. Socioemotional Development

6. Arts Development

MODULE 3 Early Childhood Health dan Nutrition

1. Early Childhood Health Definition
2. 10 Common Signs of Healthy Child

3. Early Childhood Illnesses

4. Prevention for Early Childhood Illnesses

5. Early Childhood Toilet Training

6. Nutritional Balance of Early Childhood

7. Nutritional Problems of Early Childhood

8. Slogan: Commurity's Perspective from Eating to Being Full to Eating to Being Healthy and I am What I eat

MODULE 4 Child Protection Law

1. Law on Child Protection Definition

2. Implementation of Law on Child Protection in Childcare Process

MODULE 5 Characteristics

1. Characteristics Definition for Early Childhood

2. Implemented Characteristics for Early Childhood

Figure 2. Contents of early childhood parenting module 


\section{METHOD}

This study used Research and Development method (Gall, \& Borg, 2007). Educational Research and Development (R\&D) is a process to develop and validate educational products such as the learning objectives, methods, curriculum, evaluation, both hardware and software, and procedures. The ultimate goal of R\&D learning is the appearance of new products to improve the performance of education and learning. Thus, the learning process becomes more effective and efficient and will be suitable for the demands of the needs.

The process of collecting data used qualitative and quantitative. The population in this study were parents and ECE tutors who have children up to 8 years of age who attend the BKB Sakura ECE institution in East Jakarta. Sampling used in this study was purposive sampling technique. Purposive sampling technique is a sampling technique performed by taking a subject that is not based on strata, random, and region, but based on the existence of objectives (Arikunto, 2010). Data collected by structured interviews. Furthermore, triangulation is carried out to improve the overall content and the title of the training module after several trials. And last, after the improvement process, post-test execution through the last parenting activity.

Qualitative was used to interview participants who join in parenting, both the first and second stages. In qualitative, the authors conducted a post-test in the third stage. To recheck the validity of the data, the authors used Triangulation, i.e., asked the expert about the Table of Contents of the planned module. In this study, the targeted ECE institutions were institutions that were still newly established and located in poor areas in East Jakarta.

\section{RESULT AND DISCUSSION}

This research consisted of five stages. (1) The first stage was the pre-intervention stage. At this stage, data collected from service in Rawamangun, East Jakarta, and research and service in Duren Sawit, East Jakarta in 2013, regarding parenting. The population and sample of this reserach are parents and ECE tutors in BKB Sakura, Rawamangun, East Jakarta. The population consist of 16 parents and ECE tutors. The popultion's background in this reserach are dominated by Senior High School, although there are elementary, middle school or even bachelor's degree graduate. The age of the population is about $21-49$ years. The population were single, had no children, and had three children.

Table 1. The Information of Population in This Research

\begin{tabular}{lllll}
\hline No. & Name & Age & Education & Amount of Child \\
\hline 1 & U & 33 & Bachelor's Degree & 2 \\
2 & E S H & 37 & SHS & 2 \\
3 & L B & 34 & SHS & - \\
4 & L M & 26 & MHS & 1 \\
\hline 5 & S R & 39 & SHS & 2 \\
6 & M & 28 & SHS & 2 \\
7 & W & 37 & MHS & 2 \\
8 & S & 49 & Elementary Schoold & 7 \\
\hline
\end{tabular}




\begin{tabular}{lllll}
\hline No. & Name & Age & Education & Amount of Child \\
\hline 9 & A T & 36 & Vocational High School & 1 \\
10 & E S S & 32 & Bachelor of Early Childhood Education & 2 \\
11 & D K W & 30 & Bachelor of Early Childhood Education & 2 \\
12 & A S & 33 & Vocational High School & 1 \\
13 & F A & 22 & SHS & - \\
14 & A P & 21 & SHS & Not Married Yet \\
15 & S F & 30 & SHS & 3 \\
16 & R S J & 33 & Bachelor of Early Childhood Education & 1 \\
\hline
\end{tabular}

(2) The second stage was a parenting activity titled "The Role of Parents in Educating Children Through Their Character." The activities included participants conducting Focus Group Discussion (FGD) and the execution of structured interviews. Then, it continued by providing input in preparation for making the Early Childhood Parenting Training Module.

(3) In the third stage, parenting activity titled "Early Childhood Health and Nutrition" with FGD and table of contents improvements from the FGD results were implemented to examine the first module. The fourth stage contained the second module trial activities through parenting activity with the title "Care and Protection of Early Childhood in Industry 4.0" as well as an FGD and module content improvement (table of contents) with Triangulation. In the fifth stage, module repairs were carried out. Based on input from participants and experts, the module title had improved, i.e., "Early Childhood Parenting Module - Preparing for Parenthood" with content referred to the six main aspects. Furthermore, at this stage, a post-test was also conducted to see the understanding extent of the participants after going through several steps.

Data analysis in this study was conducted to determine the extent of the understanding of 16 parents and ECE tutors regarding the main aspects of parenting. Data analysis was obtained from the results of the post-test conducted in Stage 5 (the last stage). The post-test consisted of ten multiple-choice questions consisting of five main aspects of parenting contained in the Early Childhood Parenting Training module, namely ECE Concepts Aspect, Early Childhood Development Aspect, Early Childhood Health and Nutrition, Child Protection Law, and Characteristics. Question number 1 and 2 are a question of ECE Concept, question number $3-7$ are a question of Early Childhood Health and Nutrition, question number 8 is a question of Characteristics, question number 9 is a question of Child Protection Law and question number 10 is a question of Early Childhood Development Aspect. 


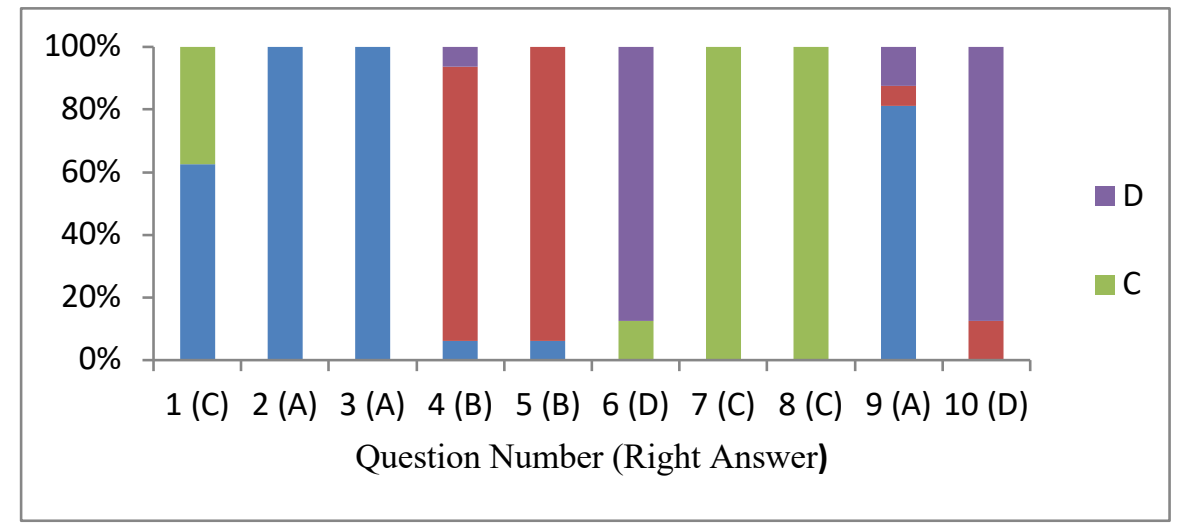

Fig 3. Post Test Answer from 16 Parents and ECE Tutors

The Diagram (Fig. 3) shows that on question 1 there are 62,5\% (10 person) parents and ECE tutors who gave incorrect answers and on question 2 and 3 all of the parents and ECE tutors chose the right answer. Question 4 there are 12,5\% (2 person) parents and ECE tutors who gave incorrect answers, on question 5 there are 6,25\% (1 person) parent and ECE tutor who incorrect answer. Question 6 there are 12,5 (2 person) parents and ECE tutor chose incorrect answers. Question 7 and 8 all of the parents and ECE tutors chose the right answers. There are 18,75\% ( 3 person) parents and ECE tutors on question 9 incorrectly chose answers. Last, on question 10 there were $12,5 \%$ (2 person) parents and ECE tutors who gave answers incorrectly.

Based on Fig. 4, it can be seen that only $13.50 \%$ of parents and ECE tutors understood the aspect of ECE Concept. In the Early Childhood Health and Nutrition aspect, $68.75 \%$ of parents and ECE tutors grasped the aspect. Based on the tabulation above, all parents and ECE tutors comprehended the aspect of Characteristics. In the aspect of Child Protection Law, $81.25 \%$ of parents and ECE tutors acknowledged the aspect. Finally, $87.50 \%$ of parents and ECE tutors apprehended the aspects of Early Childhood Development.

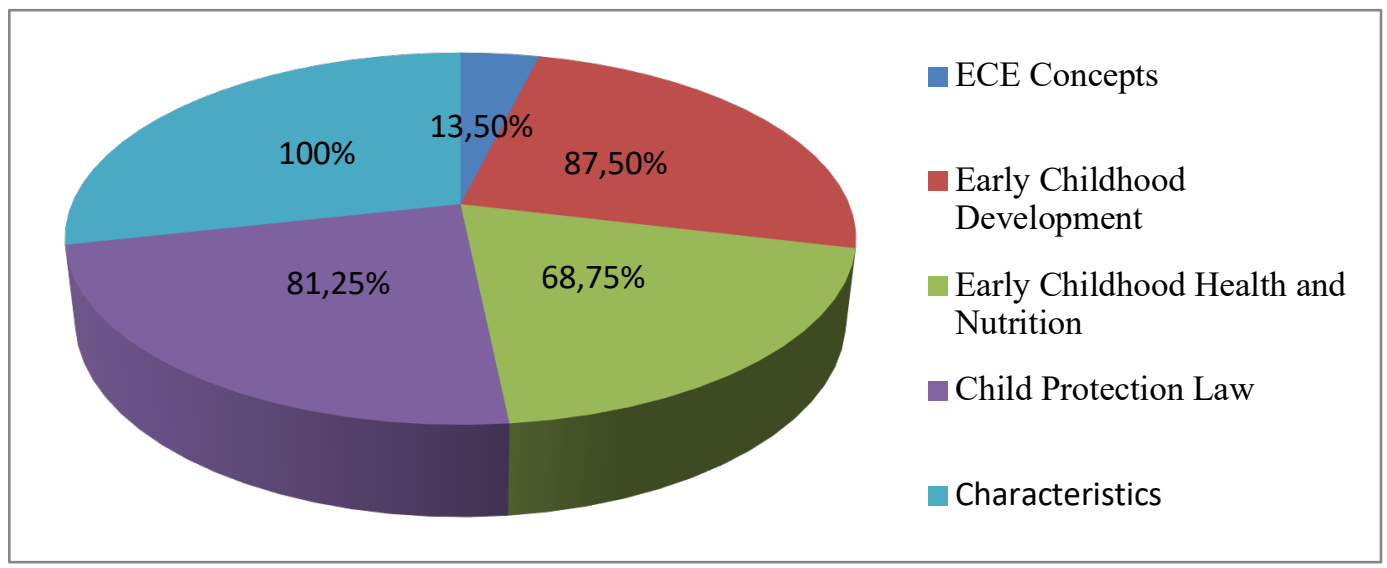

Figure 4. Main Aspects of Parenting Understanding

From the data above, the understanding and knowledge of parents and ECE tutors were already good enough but need an improvement in the aspect of Early Childhood Health Nutrition. This research focus was on studying early childhood. As we know, early childhood will encounter a golden age from birth to 8 years of age. It will affect the growth and development of early childhood whenever an error or mistake occurs in the care and nurture process that starts from a lack of knowledge or understanding of the ECE concept. In this regard, the post-test result data showed 
that there was still a lack of knowledge and understanding from parents and ECE tutors about ECE concepts. It should not be possible for parents, particularly for ECE tutors who are on duty to teach in ECE institutions daily. Thus, parents and ECE tutors need an Early Childhood Parenting Training module.

Research findings have shown that preschool programs can have a positive impact on children's cognitive, academic, and social-emotional development. But additional programs can reinforce what is delivered at school through stimulation programs that are similar at home. Parenting training modules are needed to complete the school program. In accordance with research conducted by Grindal et al., (2016) that one of the old strategies for increasing the effectiveness of preschool programs is to combine educational programs for children with additional programs for parents. Preschool-based parenting education programs provide parents with information about their child's development, and guidance on how they can provide growth-promoting activities, usually focusing on parent-child involvement that is likely to support a child's cognitive development. Although many preschool programs routinely include a parenting education component, little is known about the additional benefits of this program or whether different approaches have different impacts on children.

\section{CONCLUSION}

\subsection{Conclusion}

This study attempted to develop an early childhood parenting training model to improve life skills, especially in the parenting style of ECE parents and tutors at BKB Sakura ECE, East Jakarta. As a first step, the preliminary study concluded some initial findings related to six main aspects through community service activities and research with the same title and target in various places in East Jakarta. From the results of the preliminary study, it was concluded that ECE parents and tutors did not understand much about the six main aspects. From the initial findings, several meetings were held with ECE parents/tutors in the form of FGDs and interviews. The implementation of post-tests was also carried out to receive input from participants to complete the early childhood parenting training module. The parenting training module was intended to complement both the knowledge and application in daily life related to early childhood parenting. From these six main aspects, it seemed that the ECE parents and tutors had not understood the concept of ECE yet. It was significantly observed. In other perspectives, there was still a lack of knowledge regarding these six main aspects.

\subsection{Suggestion}

From the results of several community services regarding parenting in few ECE institutions with parents and ECE tutors as participants; then undertaking research upon parenting in Rawamangun; and conducting two experiments at the East Jakarta ECE institution, it is very explicit that parents and ECE tutors surely need training on Parenting: Preparation to Become Parents through six main aspects, and the results will be greater if equipped with the Early Childhood Parenting Training module. Thus, the training module can be required reading for ECE Institutions and parents. 


\section{REFERENCES}

Arikunto, S. (2010). Prosedur Penelitian Suatu Pendekatan Praktik. Jakarta: Asdi Mahasatya.

Britto, P. R., Lye, S. J., Proulx, K., Yousafzai, A. K., Matthews, S. G., Vaivada, T., ... Bhutta, Z. A. (2017). Nurturing care: promoting early childhood development. The Lancet, 389(10064), 91-102. https://doi.org/10.1016/S0140-6736(16)31390-3

Coore Desai, C., Reece, J. A., \& Shakespeare-Pellington, S. (2017). The prevention of violence in childhood through parenting programmes: a global review. Psychology, Health and Medicine, 22(February), 166-186. https://doi.org/10.1080/13548506.2016.1271952

Darling-Churchill, K. E., \& Lippman, L. (2016). Early childhood social and emotional development: Advancing the field of measurement. Journal of Applied Developmental Psychology, 45, 1-7. https://doi.org/10.1016/j.appdev.2016.02.002

Davis, S., Votruba-Drzal, E., \& Silk, J. S. (2015). Trajectories of Internalizing Symptoms From Early Childhood to Adolescence: Associations With Temperament and Parenting. Social Development, 24(3), 501-520. https://doi.org/10.1111/sode.12105

Đorđić, V., Tubić, T., \& Jakšić, D. (2016). The Relationship between Physical, Motor, and Intellectual Development of Preschool Children. Procedia - Social and Behavioral Sciences, 233(May), 3-7. https://doi.org/10.1016/j.sbspro.2016.10.114

Eisenberg, N., Taylor, Z. E., Widaman, K. F., \& Spinrad, T. L. (2015). Externalizing symptoms, effortful control, and intrusive parenting: A test of bidirectional longitudinal relations during early childhood. Development and Psychopathology, 27(4), 953-968. https://doi.org/10.1017/S0954579415000620

Gall, M. D., Gall, J. P., \& Borg, W. R. (2007). Educational Research: An Introduction (4th ed.). New York: Longman Inc.

Gardner, F., Montgomery, P., \& Knerr, W. (2016). Transporting Evidence-Based Parenting Programs for Child Problem Behavior (Age 3-10) Between Countries: Systematic Review and Meta-Analysis. Journal of Clinical Child and Adolescent Psychology, 45(6), 749-762. https://doi.org/10.1080/15374416.2015.1015134

Gilmer, C., Buchan, J. L., Letourneau, N., Bennett, C. T., Shanker, S. G., Fenwick, A., \& SmithChant, B. (2016). Parent education interventions designed to support the transition to parenthood: A realist review. International Journal of Nursing Studies, 59, 118-133. https://doi.org/10.1016/j.ijnurstu.2016.03.015

Grindal, T., Bowne, J. B., Yoshikawa, H., Schindler, H. S., Duncan, G. J., Magnuson, K., \& Shonkoff, J. P. (2016a). The added impact of parenting education in early childhood education programs: A meta-analysis. Children and Youth Services Review, 70, 238-249. https://doi.org/10.1016/j.childyouth.2016.09.018

Grindal, T., Bowne, J. B., Yoshikawa, H., Schindler, H. S., Duncan, G. J., Magnuson, K., \& Shonkoff, J. P. (2016b). The added impact of parenting education in early childhood education programs: A meta-analysis. Children and Youth Services Review, 70(December 2017), 238-249. https://doi.org/10.1016/j.childyouth.2016.09.018

Guyer, A. E., Jarcho, J. M., Pérez-Edgar, K., Degnan, K. A., Pine, D. S., Fox, N. A., \& Nelson, E. E. (2015). Temperament and Parenting Styles in Early Childhood Differentially Influence Neural Response to Peer Evaluation in Adolescence. Journal of Abnormal Child Psychology, 43(5), 863-874. https://doi.org/10.1007/s10802-015-9973-2

Jones, D. E., Feinberg, M. E., Hostetler, M. L., Roettger, M. E., Paul, I. M., \& Ehrenthal, D. B. (2018). Family and Child Outcomes 2 Years After a Transition to Parenthood Intervention. Family Relations, 67(2), 270-286. https://doi.org/10.1111/fare.12309

Jürges, H., Schwarz, A., Cahan, S., \& Abdeen, Z. (2019). Child mental health and cognitive 
development: evidence from the West Bank. Empirica, 46(3), 423-442. https://doi.org/10.1007/s10663-019-09438-5

Kalland, M., Fagerlund, Å., Von Koskull, M., \& Pajulo, M. (2016). Families First: The development of a new mentalization-based group intervention for first-Time parents to promote child development and family health. Primary Health Care Research and Development, 17(1), 3-17. https://doi.org/10.1017/S146342361500016X

Knauer, H. A., Ozer, E. J., Dow, W. H., \& Fernald, L. C. H. (2019). Parenting quality at two developmental periods in early childhood and their association with child development. Early Childhood Research Quarterly, 47, 396-404. https://doi.org/10.1016/j.ecresq.2018.08.009

Kopala-Sibley, D. C., Cyr, M., Finsaas, M. C., Orawe, J., Huang, A., Tottenham, N., \& Klein, D. N. (2018). Early Childhood Parenting Predicts Late Childhood Brain Functional Connectivity During Emotion Perception and Reward Processing. Child Development, 00(0), 1-19. https://doi.org/10.1111/cdev.13126

Kurniah, N., Andreswari, D., \& Kusumah, R. G. T. (2019). Achievement of Development on Early Childhood Based on National Education Standard. 295(ICETeP 2018), 351-354. https://doi.org/10.2991/icetep-18.2019.82

Leijten, P., Raaijmakers, M. A. J., Orobio de Castro, B., van den Ban, E., \& Matthys, W. (2017). Effectiveness of the Incredible Years Parenting Program for Families with Socioeconomically Disadvantaged and Ethnic Minority Backgrounds. Journal of Clinical Child and Adolescent Psychology, 46(1), 59-73. https://doi.org/10.1080/15374416.2015.1038823

Lomanowska, A. M., Boivin, M., Hertzman, C., \& Fleming, A. S. (2017). Parenting begets parenting: A neurobiological perspective on early adversity and the transmission of parenting styles across generations. Neuroscience, 342, 120-139. https://doi.org/10.1016/j.neuroscience.2015.09.029

Lucassen, N., Kok, R., Bakermans-Kranenburg, M. J., Van Ijzendoorn, M. H., Jaddoe, V. W. V., Hofman, A., ... Tiemeier, H. (2015). Executive functions in early childhood: The role of maternal and paternal parenting practices. British Journal of Developmental Psychology, 33(4), 489-505. https://doi.org/10.1111/bjdp.12112

Molchanov, S. V. (2013). The Moral Development in Childhood. Procedia - Social and Behavioral Sciences, 86, 615-620. https://doi.org/10.1016/j.sbspro.2013.08.623

Morris, A. S., \& Williamson, A. C. (2019). Building early social and emotional relationships with infants and toddlers: Integrating research and practice. Building Early Social and Emotional Relationships with Infants and Toddlers: Integrating Research and Practice, 1-351. https://doi.org/10.1007/978-3-030-03110-7

Parhomenko, K. (2014). Diagnostic Methods of Socio - Emotional Competence in Children. Procedia - Social and Behavioral Sciences, 146, 329-333. https://doi.org/10.1016/j.sbspro.2014.08.142

Rutherford, H. J. V., Wallace, N. S., Laurent, H. K., \& Mayes, L. C. (2015). Emotion regulation in parenthood. Developmental Review, 36, 1-14. https://doi.org/10.1016/j.dr.2014.12.008

Sheedy, A., \& Gambrel, L. E. (2019). Coparenting Negotiation During the Transition to Parenthood: A Qualitative Study of Couples' Experiences as New Parents. American Journal of Family Therapy, 47(2), 67-86. https://doi.org/10.1080/01926187.2019.1586593

Sitnick, S. L., Shaw, D. S., Gill, A., Dishion, T., Winter, C., Waller, R., ... Wilson, M. (2015). Parenting and the Family Check-Up: Changes in Observed Parent-Child Interaction Following Early Childhood Intervention. Journal of Clinical Child and Adolescent Psychology, 44(6), 970-984. https://doi.org/10.1080/15374416.2014.940623 
Sulik, M. J., Blair, C., Mills-Koonce, R., Berry, D., \& Greenberg, M. (2015). Early Parenting and the Development of Externalizing Behavior Problems: Longitudinal Mediation Through Children's Executive Function. Child Development, 86(5), 1588-1603. https://doi.org/10.1111/cdev.12386

Theise, R., Huang, K. Y., Kamboukos, D., Doctoroff, G. L., Dawson-McClure, S., Palamar, J. J., \& Brotman, L. M. (2014). Moderators of Intervention Effects on Parenting Practices in a Randomized Controlled Trial in Early Childhood. Journal of Clinical Child and Adolescent Psychology, 43(3), 501-509. https://doi.org/10.1080/15374416.2013.833095

UNDP. (2018). Human Development Indices and Indicators. 2018 Statistical Update. United Nations Development Programme, 27(4), 123. Retrieved from http://hdr.undp.org/sites/default/files/2018_human_development_statistical_update.pdf $\% 0$ Ahttp://www.hdr.undp.org/sites/default/files/2018 human development statistical update .pdf\%0Ahttp://hdr.undp.org/en/2018-update 